\title{
Pertumbuhan, Produksi Biomassa, dan Kandungan Glikosida Steviol pada Lima Klon Stevia Introduksi di Bogor, Indonesia
}

\author{
Growth, Biomass Production, and Steviol Glycoside Contents of \\ Five Introduced Clones of Stevia in Bogor, Indonesia
}

\author{
Masna Maya Sinta $^{1}$ dan Sumaryono ${ }^{1^{*}}$ \\ ${ }^{1}$ Pusat Penelitian Bioteknologi dan Bioindustri Indonesia \\ Jl. Taman Kencana No.1, Bogor 16128, Indonesia \\ Diterima 15 Maret 2018/Disetujui 6 Desember 2018
}

\begin{abstract}
Stevia rebaudiana Bertoni, a sweetener plant, has been cultivated in Indonesia since the early 1980s, but the yield is lower than in other countries. Five selected introduced stevia clones were planted at Megamendung, Bogor, Indonesia (6 $6^{\circ} 9^{\prime}$, S, 106 56' E, $800 \mathrm{~m}$ above sea level) on December 2014 until November 2015 to evaluate their growth and biomass yield. The growth and yield were observed from 6 to 12 months after planting. In addition, stevioside, rebaudioside A (reb A), and total steviol glycoside (TSG) contents of leaves were measured using high performance liquid chromatography (HPLC). At six months after planting, stem diameter was 8-11 mm, plant canopy diameter was 23-30 cm, plant height was 24-35 cm, and plant mortality was less than $5 \%$ except for clone BU at 30.7\% due to Sclerotium attack. The plants flowered at different times, therefore had different harvest durations, from 4 weeks (clone BM) to 8 weeks (clone BP). The highest leaf yield was clone $B M$ (6.04 ton ha-1 per year), followed by $B X$ (4.91 ton ha $a^{-1}$ per year), and BP (4.38 ton ha-1 per year). From the five clones tested, clone BM was the best for leaf, TSG, and stevioside yields; whereas clone BS and BP were the best for reb $A$ yield.
\end{abstract}

Keywords: rebaudioside A, Stevia rebaudiana, stevioside, total steviol glycoside

\section{ABSTRAK}

Stevia rebaudiana Bertoni, tanaman pemanis, telah dibudidayakan di Indonesia sejak awal tahun 1980-an, namun produktivitasnya lebih rendah dibandingkan dengan di negara lain. Lima klon stevia introduksi terpilih diuji-lapang di Megamendung, Bogor, Indonesia (6 $6^{\circ} 39^{\prime} \mathrm{LS}, 106^{\circ} 56^{\prime} \mathrm{BT}, 800 \mathrm{~m}$ di atas permukaan laut) pada bulan Desember 2014 hingga November 2015 untuk mengkaji pertumbuhan dan produksi biomassanya. Pertumbuhan dan hasil tanaman diamati pada umur 6 bulan sampai 12 bulan setelah tanam. Selain itu, diukur kandungan steviosida, rebaudiosida A (reb A), dan total glikosida steviol (TSG) di dalam daun menggunakan kromatografi cair kinerja tinggi (KCKT). Pada umur enam bulan setelah tanam, diameter batang mencapai 8-11 mm, diameter tajuk tanaman 23-30 cm, tinggi tanaman 24-35 cm, dan persentase kematian tanaman kurang dari $5 \%$ kecuali klon BU pada tingkat 30.7\% karena adanya serangan penyakit Sclerotium. Kelima klon stevia mulai berbunga pada waktu yang berbeda sehingga periode panen juga berbeda dari 4 minggu (klon BM) sampai 8 minggu (klon BP). Hasil daun kering tertinggi diperoleh pada klon BM (6.04 ton ha ${ }^{-1}$ per tahun), diikuti oleh BX (4.91 ton ha ${ }^{-1}$ per tahun), dan BP (4.38 ton ha ${ }^{-1}$ per tahun). Berdasarkan kelima klon stevia yang diuji, klon BM terbaik dalam menghasilkan daun, TSG, dan steviosida; sedangkan klon BS dan BP terbaik dalam menghasilkan reb A.

Kata kunci: rebaudiosida A, Stevia rebaudiana, steviosida, total glikosida steviol

\section{PENDAHULUAN}

Stevia (Stevia rebaudiana Bertoni) adalah tanaman pemanis berbentuk perdu famili Asteraceae berasal dari Paraguay. Gula stevia memiliki beberapa keunggulan antara lain bersifat alami, sangat manis (200-300 kali lebih manis dari gula tebu), tidak mengandung kalori, dan memiliki

\footnotetext{
* Penulis untuk korespondensi. e-mail: sumaryono@iribb.org
}

indeks glikemik nol (Mogra dan Dashora, 2009). Kelebihan tersebut menjadikan gula stevia sesuai untuk penderita diabetes, obesitas atau kegemukan, seseorang yang sensitif terhadap pemanis sintetik, dan yang peduli terhadap kesehatan.

Stevia mempunyai daya adaptasi lingkungan yang sangat luas. Di daerah asalnya, stevia tumbuh di wilayah subtropis $22-24{ }^{\circ} \mathrm{LS}$, ketinggian tempat $500-1,500 \mathrm{~m}$ di atas permukaan laut (dpl) dengan kisaran suhu $17-26{ }^{\circ} \mathrm{C}$ 
(Kinghorn, 2002). Tanaman stevia tumbuh dengan baik dari daerah tropis maupun subtropis sampai St. Petersburg, Rusia pada $60^{\circ} \mathrm{LU}$ dengan suhu musim dingin sampai dengan $-3^{\circ} \mathrm{C}$ (Ramesh et al., 2006). Di daerah tropis stevia umumnya ditanam di dataran tinggi 800-2,000 m dpl dengan suhu 20-30 ${ }^{\circ} \mathrm{C}$. Curah hujan optimum untuk stevia antara 1,500 sampai 2,300 mm per tahun dengan maksimum 3 bulan kering (Kinghorn, 2002). Kondisi tanah yang ideal untuk pertumbuhan stevia adalah $\mathrm{pH}$ 5-7, kapasitas menahan air baik, drainase baik, dan mengandung bahan organik yang cukup (Ramesh et al., 2006). Stevia tidak toleran terhadap lahan dengan $\mathrm{pH}$ tinggi sehingga sebaiknya tidak ditanam pada lahan basa.

Penentu kemanisan stevia adalah kandungan glikosida steviol di dalam daun stevia. Sampai saat ini telah ditemukan 34 jenis glikosida steviol, namun hanya 11 glikosida steviol yang umum ditemukan pada tanaman stevia (Ceunen et al., 2012; Ceunen dan Geuns, 2013a). Steviosida dan rebaudiosida A (reb A) merupakan jenis glikosida steviol yang paling dominan pada stevia (Chatsudthipong dan Muanprasat, 2009; Yadav dan Guleria 2012; Prakash et al., 2014). Produktivitas klon stevia lokal Indonesia, seperti klon seri BPP hanya sekitar 2.5-3.5 ton daun kering ha-1 per tahun dengan kandungan steviosida $6.2-15.1 \%$ dan reb $\mathrm{A}$ 0.4-3.7\% (Suhendi, 1988). Produktivitas klon unggul stevia di Amerika mencapai lebih dari 5 ton daun kering ha ${ }^{-1}$ per tahun dengan kandungan total steviol glycoside (TSG) 15\% dan reb A 9\% (Parris et al., 2016), bahkan ada varietas baru yang dinyatakan memiliki TSG $21 \%$ dengan reb A $16 \%$ (Shock dan Parris, 2015, 2016).

Klon stevia generasi lama umumnya memiliki kandungan steviosida tinggi dan reb A rendah, namun sebaliknya pada klon generasi baru. Kandungan reb A penting karena memiliki tingkat kemanisan tinggi, rasa mendekati gula tebu, dan relatif tidak meninggalkan rasa pahit (bitter aftertaste) (Prakash et al., 2014). Pengembangan stevia di Indonesia sebaiknya menggunakan klon stevia introduksi agar mampu bersaing dengan negara produsen lainnya. Klon stevia unggul introduksi tersebut harus diuji adaptasi untuk mendapatkan klon atau varietas yang adaptif dengan tanah dan iklim Indonesia. Klon introduksi terpilih selanjutnya dapat diperbanyak secara cepat dan massal dengan teknik kultur jaringan (Sumaryono dan Sinta, 2011).

Penelitian ini bertujuan untuk mengkaji daya adaptasi, pertumbuhan, produksi serta kandungan TSG, steviosida, dan reb A tanaman stevia asal biji dari luar negeri yang telah diseleksi dan diperbanyak secara klonal dengan kultur jaringan.

\section{BAHAN DAN METODE}

Penelitian dilakukan di daerah Megamendung, Kabupaten Bogor, Jawa Barat (6³9' LS, 106 $56^{\circ}$ BT), pada ketinggian $800 \mathrm{~m}$ dpl dengan curah hujan rata-rata 2,536 mm per tahun, suhu rata-rata $25.7{ }^{\circ} \mathrm{C}$, kisaran suhu 22.4$31.4{ }^{\circ} \mathrm{C}$, dan tanah berjenis andosol dengan $\mathrm{pH} 6.1$.

Benih stevia dari 5 genotipe yang berbeda diperoleh dari Kanada dan Peru. Benih stevia kemudian dikecambahkan di dalam cawan petri dengan alas kertas saring. Kecambah yang tumbuh kemudian dikultur secara in vitro. Planlet yang tumbuh dengan baik selanjutnya diaklimatisasi pada tray 128 lubang ukuran $3 \mathrm{~cm} \times 3 \mathrm{~cm} \times 3 \mathrm{~cm}$ berisi media campuran tanah, cocopeat, dan pupuk kandang (3:1:1) yang diletakkan di dalam sungkup plastik tertutup selama 3-4 minggu. Bibit yang sudah berakar selanjutnya ditanam di lapang. Tanaman yang tumbuh paling baik diseleksi dan digunakan sebagai bahan tanam. Bibit hasil seleksi dari 5 varietas selanjutnya masing-masing dinamakan sebagai klon BM, BP, BS, BU, dan BX. Kelima klon tersebut diperbanyak secara vegetatif dengan setek di lapang.

Penelitian ini dilakukan pada bulan Desember 2014 sampai dengan Juli 2015. Bibit stevia ditanam pada bedengan berukuran $1 \mathrm{~m} \times 8 \mathrm{~m}$ dan tinggi bedengan $15 \mathrm{~cm}$. Permukaan bedengan ditutupi dengan mulsa plastik yang dilubangi dengan diameter $3 \mathrm{~cm}$ sebagai tempat tumbuh bibit. Sebelum ditutup plastik, setiap bedengan diberi pupuk kandang ayam dengan dosis $20,000 \mathrm{~kg} \mathrm{ha}^{-1}$. Tiap bedengan terdiri atas 128 tanaman dengan jarak tanam $25 \mathrm{~cm} \times 25$ $\mathrm{cm}$. Penelitian ini menggunakan Rancangan Kelompok Lengkap Teracak (RKLT) satu faktor dengan 4 ulangan. Tanaman dipangkas pertama kali pada umur 1 bulan setelah tanam pada ketinggian $15 \mathrm{~cm}$ di atas permukaan tanah. Pemangkasan berikutnya dilakukan setelah sebagian tanaman mulai berbunga $(5-10 \%$ dari populasi tanaman telah berbunga).

Pengamatan pertumbuhan dan hasil mulai dilakukan 6 bulan setelah tanam yaitu saat tanaman mulai berproduksi dengan stabil. Karakter pertumbuhan tanaman yang diamati pada saat tanaman berumur 6 bulan adalah diameter batang $(\mathrm{cm})$, diameter tajuk $(\mathrm{cm})$, tinggi tanaman $(\mathrm{cm})$, dan persentase kematian tanaman (\%). Karakter hasil yang diamati terdiri atas waktu munculnya bunga setelah panen terakhir (minggu), bobot biomassa kering panen (g), dan bobot daun kering (g). Frekuensi panen dilakukan berdasarkan pada kecepatan klon tanaman mulai berbunga, dengan cara memangkas sekitar $1 \mathrm{~cm}$ di atas pangkasan akhir menggunakan gunting stek. Pengamatan hasil stevia dilakukan selama 6 bulan. Bobot biomassa kering dan bobot daun kering ditentukan berdasarkan total panen tiap klon setelah 6 bulan. Perkiraan hasil daun kering ditentukan dengan mengkonversi rata-rata produksi daun kering, jumlah panen selama setahun dengan populasi tanam. Perkiraan populasi tanaman per hektar dihitung dengan asumsi penggunan lahan efektif 60\% (setelah dikurangi jarak antar bedengan dan infrastruktur), sehingga populasi bibit stevia dihitung dengan rumus adjustment per hektar $=$ $60 \% \times(10,000: 8) \times 128=96,000$ tanaman.

Analisis kandungan steviosida, reb A, dan TSG dalam daun stevia setiap klon menggunakan High Performance Liquid Chromatography (HPLC) dilakukan di Daepyung, Korea menggunakan metode dari JECFA (FAO, 2010).

\section{Analisis Data}

Data pengamatan diuji statistik menggunakan sidik ragam (analysis of variance atau ANOVA). Apabila 
terdapat perbedaan yang nyata antar klon pada karakter yang diamati, maka diuji lanjut dengan uji jarak berganda Duncan (DMRT) pada taraf $\alpha=0.05$.

\section{HASIL DAN PEMBAHASAN}

\section{Pertumbuhan Tanaman}

Pengamatan pertumbuhan tanaman stevia dilakukan pada umur 6 bulan setelah tanam, disajikan pada Tabel 1 . Klon BX memiliki diameter batang utama terbesar yaitu rata-rata $10.5 \mathrm{~mm}$ sedangkan diameter batang terkecil pada klon BP yaitu $7.9 \mathrm{~mm}$ (Tabel 1). Diameter batang menunjukkan kekokohan dari tanaman stevia. Diameter batang menunjang struktur percabangan stevia untuk menghasilkan biomassa daun. Kelima klon yang diuji mempunyai struktur percabangan dengan satu batang utama dan beberapa cabang sekunder. Hal ini berbeda dengan percabangan tanaman stevia lokal di Tawangmangu maupun di Belgia (Ceunen dan Geuns, 2013b) yang umumnya tidak memiliki batang utama tetapi banyak cabang yang langsung tumbuh dari bonggol di permukaan tanah.

Diameter tajuk memperlihatkan cakupan tajuk tanaman dalam menutup permukaan tanah. Diameter tajuk terbesar pada klon BS yaitu $30.4 \mathrm{~cm}$, sedangkan terkecil adalah klon BU yaitu $23.3 \mathrm{~cm}$. Dengan jarak tanam $25 \mathrm{~cm}$ x $25 \mathrm{~cm}$ maka semua klon stevia yang diuji telah menutup permukaan tanah, kecuali stevia klon BU (Tabel 1). Kemampuan tajuk stevia menutup permukaan tanah akan mengurangi pertumbuhan gulma yang muncul dari lubang tanam (Sumaryono dan Sinta, 2015).

Tinggi tanaman memperlihatkan tinggi perdu stevia saat akan dipangkas, yang berkisar antara $24-35 \mathrm{~cm}$ dari atas permukaan tanah. Tinggi tanaman stevia klon BM dan BS sekitar $24 \mathrm{~cm}$, sedangkan ketiga klon lainnya sekitar $35 \mathrm{~cm}$ (Tabel 1). Tinggi tanaman klon BM dan BS yang lebih rendah ini berkaitan dengan lebih seringnya periode panen dari kedua klon ini yakni setiap 4-5 minggu, sedangkan ketiga klon lainnya setiap 6-8 minggu (Tabel 3). Dibandingkan dengan stevia di daerah subtropis, tanaman stevia tropis lebih pendek. Hal ini karena frekuensi panen yang lebih sering. Tanaman stevia tumbuh jauh lebih tinggi di daerah subtropis seperti di India berkisar 36-65 cm (Kumar et al., 2014), sedangkan di Bulgaria mencapai 80$120 \mathrm{~cm}$ (Nikolova, 2015).
Tanaman stevia yang mati disulam sampai tanaman berumur 2 bulan, setelah itu tidak lagi. Setelah tanaman berumur 6 bulan, frekuensi kematian tanaman stevia sekitar 5\%, kecuali pada klon BU mencapai 30.7\% (Tabel 1). Tingginya kematian klon BU karena terserang penyakit Sclerotium rolfsii. Serangan Sclerotium rolfsii pada stevia telah dilaporkan di India (Kamalakannan et al., 2007), Amerika Serikat (Koehler dan Shew, 2014), dan Italia (Carrieri et al., 2016) dengan periode penyebaran umumnya terjadi dari Mei hingga musim panas berakhir. Gejala penyakit ini diawali dengan kelayuan pada tunas muda kemudian terjadi klorosis pada daun, selanjutnya batang akan mati dan akar membusuk, dengan miselium berwarna putih ditemukan pada pangkal batang.

\section{Produksi Biomassa}

Produksi biomassa daun kering stevia antara klon yang berbeda pada setiap kali panen menunjukkan fluktuasi yang cukup besar (Tabel 2). Selama 6 bulan, tanaman stevia klon BM dipanen sebanyak 6 kali, klon BS sebanyak 5 kali, klon BU dan BX sebanyak 4 kali dan klon BP hanya 3 kali. Hal ini menunjukkan bahwa klon BM paling cepat berbunga (4 minggu setelah pangkas), sedangkan klon BP paling lambat berbunga (8-10 minggu setelah pangkas) (Tabel 3). Daun stevia dipanen pada saat tanaman mulai berbunga karena pada tahap perkembangan ini kandungan glikosida steviol paling tinggi (Ceunen dan Geuns, 2013b).

Hasil biomassa daun kering stevia per tanaman beragam antar klon dan periode panen. Bobot kering daun setiap kali panen berkisar antara $2 \mathrm{~g}$ sampai dengan $10.6 \mathrm{~g}$ per tanaman. Bobot daun kering terendah pada klon BM pada panen pertama sedangkan tertinggi pada klon BP pada panen pertama. Namun, hasil klon BM pada panen ke-2 meningkat tiga kali lipat, sedangkan hasil klon BP pada panen ke-2 menurun. Secara keseluruhan, produktivitas daun kering klon stevia per tanaman tersebut masih lebih rendah dibandingkan di negara subtropis. Produktivitas daun kering di India mencapai 15-35 g per tanaman (Mishra et al., 2010) dan 20.7 g per tanaman (Kumar et al., 2014), bahkan di Bulgaria dapat mencapai 50-70 g per tanaman (Nikolova, 2015), dengan frekuensi panen hanya 2-4 kali per tahun. Hasil biomassa daun stevia sangat tergantung pada varietas dan lingkungan penanaman (Parris et al., 2016).

Tabel 1. Pertumbuhan tanaman lima klon stevia pada umur enam bulan

\begin{tabular}{lcccc}
\hline Klon stevia & Diameter batang $(\mathrm{mm})$ & Diameter tajuk $(\mathrm{cm})$ & Tinggi tanaman $(\mathrm{cm})$ & Kematian tanaman $(\%)$ \\
\hline BM & $9.7 \mathrm{ab}$ & $29.7 \mathrm{ab}$ & $24.2 \mathrm{~b}$ & $0.2 \mathrm{~b}$ \\
$\mathrm{BP}$ & $7.9 \mathrm{c}$ & $27.8 \mathrm{ab}$ & $35.1 \mathrm{a}$ & $5.0 \mathrm{~b}$ \\
$\mathrm{BS}$ & $8.8 \mathrm{bc}$ & $30.4 \mathrm{a}$ & $24.5 \mathrm{~b}$ & $3.5 \mathrm{~b}$ \\
$\mathrm{BU}$ & $8.8 \mathrm{bc}$ & $23.3 \mathrm{c}$ & $35.4 \mathrm{a}$ & $30.7 \mathrm{a}$ \\
$\mathrm{BX}$ & $10.5 \mathrm{a}$ & $26.9 \mathrm{~b}$ & $34.3 \mathrm{a}$ & $5.2 \mathrm{a}$ \\
\hline
\end{tabular}

Keterangan: Angka-angka pada kolom yang sama yang diikuti oleh huruf yang sama tidak berbeda nyata berdasarkan uji DMRT pada $\alpha=$ 0.05 
Tabel 2. Hasil biomassa daun kering per tanaman dan frekuensi panen stevia selama enam bulan

\begin{tabular}{|c|c|c|c|c|c|c|c|c|}
\hline \multirow{2}{*}{ Klon } & \multicolumn{6}{|c|}{ Panen ke- (g daun per tanaman) } & \multirow{2}{*}{$\begin{array}{c}\text { Jumlah } \\
\text { panen }\end{array}$} & \multirow{2}{*}{$\begin{array}{c}\text { Rerata hasil daun } \\
\text { (g/panen per } \\
\text { tanaman) }\end{array}$} \\
\hline & 1 & 2 & 3 & 4 & 5 & 6 & & \\
\hline $\mathrm{BM}$ & 2.0 & 6.9 & 4.7 & 8.3 & 4.6 & 5.3 & 6 & 5.3 \\
\hline BP & 10.6 & 3.7 & 10.2 & - & - & - & 3 & 8.2 \\
\hline BS & 3.2 & 5.2 & 6.1 & 4.0 & 3.5 & - & 5 & 4.4 \\
\hline BU & 2.6 & 3.4 & 2.7 & 4.0 & - & - & 4 & 3.2 \\
\hline $\mathrm{BX}$ & 4.6 & 8.1 & 5.8 & 7.8 & - & - & 4 & 6.6 \\
\hline
\end{tabular}

Keterangan: - = tidak panen (pertumbuhan)

Kecepatan setiap klon stevia untuk mulai berbunga sangat beragam sehingga panen untuk setiap klon juga berbeda-beda. Panen biomassa (daun dan batang bagian atas) dilakukan pada waktu tanaman mulai berbunga. Hal ini disebabkan kandungan glikosida steviol akan menurun setelah tanaman berbunga, sebaliknya jika tanaman terlalu cepat dipanen, produksi biomassa daun masih rendah. Klon stevia yang paling cepat berbunga adalah klon BM yakni 4 minggu setelah panen terakhir, dan yang paling lambat berbunga adalah klon BP yakni setiap 8-10 minggu setelah panen. Lingkungan produksi mempengaruhi kecepatan tanaman stevia berbunga, pada wilayah subtropis tanaman stevia hanya berbunga satu kali menjelang musim dingin, sedangkan pada wilayah tropis bergantung pada ketinggian tempat (altitute). Tanaman stevia lebih cepat berbunga di dataran rendah wilayah tropis dibandingkan dengan di dataran tinggi (Mubiyanto, 1990).

Stevia termasuk tanaman hari pendek (short-day plant), yang berarti tanaman akan terinduksi untuk berbunga apabila periode siang hari kurang dari panjang hari kritisnya (critical day length). Panjang hari kritis pada tanaman stevia adalah 13 jam. Stevia cepat berbunga di daerah subtropis pada musim dingin, sehingga tanaman hanya dipanen satu atau dua kali per tanam saat musim panas. Kecepatan tanaman stevia berbunga di Indonesia tidak bergantung pada musim karena memiliki panjang hari yang relatif sama. Stevia dapat dipanen 6-12 kali per tahun selama satu siklus hidup 2-4 tahun. Hasil ini sesuai dengan yang diungkapkan oleh Djajadi (2014) bahwa stevia di Indonesia umumnya dipanen setiap 30-60 hari. Pereira et al. (2016) menyatakan bahwa semakin panjang lama penyinaran, semakin panjang periode panen.

Produktivitas biomassa daun dan batang tertinggi dicapai oleh klon BM, disusul klon BX, BP, dan BS (Tabel 3). Hal ini mengindikasikan bahan klon BP paling efisien dengan tingkat produksi cukup tinggi. Hasil daun hampir sama dengan hasil biomassa, dengan rendemen daun sekitar $74-81 \%$ dari total biomassa (Tabel 4). Karena bagian tanaman stevia yang mengandung glikosida steviol paling tinggi adalah daun maka produktivitas daun tanaman stevia yang paling penting. Hasil tertinggi diperoleh dari klon BM yakni dengan potensi produksi sebesar $4.03 \mathrm{~kg}$ daun kering per $8 \mathrm{~m}^{2}$ selama 6 bulan atau setara 6.04 ton daun kering ha $^{-1}$ per tahun diikuti klon BX 4.91 ton daun kering ha-1 per tahun dan klon BP 4.38 ton daun kering ha $\mathrm{h}^{-1}$ per tahun (Tabel 3). Produksi daun ini lebih tinggi dibandingkan dengan produksi daun klon unggul stevia seri BPP sebesar 2.5-3.5 ton $\mathrm{ha}^{-1}$ per tahun (Suhendi, 1988).

Di negara subtropis waktu panen lebih lambat, dengan frekuensi panen 1-2 kali per periode tanam. Di Bulgaria, stevia dipanen 2-3 kali per tahun dengan tinggi tanaman mencapai $80-120 \mathrm{~cm}$, dan total hasil daun kering 2.5-3.0 ton ha $^{-1}$ per tahun (Nikolova, 2015). Di Amerika Serikat, dari uji lapang beberapa kultivar stevia di empat lokasi menunjukkan produksi daun rata-rata 4.12 ton ha $^{-1}$ per tahun, bahkan ada yang mencapai 7 ton ha $\mathrm{h}^{-1}$ per tahun dengan frekuensi panen satu atau dua kali (Parris et al., 2016), sedangkan di wilayah subtropis Brazil hasil daun mencapai 4.0 ton ha-1

Tabel 3. Durasi panen, jumlah panen per tahun, hasil biomassa, dan daun kering stevia per tahun

\begin{tabular}{lcccccc}
\hline Klon & $\begin{array}{c}\text { Durasi panen } \\
(\text { minggu })\end{array}$ & $\begin{array}{c}\text { Jumlah panen } \\
\text { per tahun }\end{array}$ & $\begin{array}{c}\text { Bobot biomassa } \\
\text { kering }(\mathrm{kg})\end{array}$ & $\begin{array}{c}\text { Bobot daun } \\
\text { kering }(\mathrm{kg})\end{array}$ & $\begin{array}{c}\text { Perkiraan hasil } \\
\text { daun kering } \\
\left(\text { ton ha }^{-1}\right)\end{array}$ & $\begin{array}{c}\text { Rendemen daun } \\
(\%)\end{array}$ \\
\hline BM & 4 & 13 & $5.47 \mathrm{a}$ & $4.03 \mathrm{a}$ & $6.04 \mathrm{a}$ & $73.6 \mathrm{~b}$ \\
$\mathrm{BP}$ & 8 & 6 & $3.61 \mathrm{bc}$ & $2.92 \mathrm{bc}$ & $4.38 \mathrm{bc}$ & $81.0 \mathrm{a}$ \\
$\mathrm{BS}$ & 5 & 10 & $3.47 \mathrm{c}$ & $2.70 \mathrm{c}$ & $4.06 \mathrm{c}$ & $78.3 \mathrm{a}$ \\
$\mathrm{BU}$ & 7 & 7 & $1.56 \mathrm{~d}$ & $1.09 \mathrm{~d}$ & $1.63 \mathrm{~d}$ & $78.0 \mathrm{a}$ \\
$\mathrm{BX}$ & 6 & 8 & $3.96 \mathrm{~b}$ & $3.27 \mathrm{~b}$ & $4.91 \mathrm{~b}$ & $79.2 \mathrm{a}$ \\
\hline
\end{tabular}

Keterangan: Angka-angka pada kolom yang sama yang diikuti oleh huruf yang sama tidak berbeda nyata berdasarkan uji DMRT pada $\alpha=0.05$ 
per tahun dengan panen 1-3 kali (Pereira et al., 2016). Penanaman stevia di daerah tropis seperti Indonesia lebih menguntungkan dari segi kumulatif produksi, namun panen yang lebih sering meningkatkan biaya panen.

\section{Produksi Glikosida Steviol}

Analisis kandungan total glikosida steviol daun kelima klon stevia introduksi memperlihatkan kandungan yang beragam antara $6.7 \%$ sampai dengan $13.5 \%$ (Tabel 4 ). Tingkat kandungan TSG ini relatif sedang, kecuali klon BU yang hanya $6.7 \%$ yang tergolong rendah. Dua komponen TSG utama adalah steviosida dan reb A, yang berkisar 77$82 \%$ dari TSG, kecuali klon BU sebesar 57\%. Kandungan steviosida tinggi adalah klon BM (4.10\%) dan klon BX (4.06\%), sedangkan kandungan reb A tinggi adalah klon BS $(8.54 \%)$ dan klon BP (6.62\%). Klon BP mempunyai proporsi reb A tinggi dalam TSG yakni $67.3 \%$. Kandungan dan proporsi reb A yang tinggi lebih diutamakan karena tingkat kemanisannya lebih tinggi dari steviosida dan tidak meninggalkan rasa pahit (bitter aftertaste) yang merupakan karakter yang tidak diinginkan terutama apabila untuk minuman dan makanan.

Berbagai faktor mempengaruhi produktivitas dan kandungan glikosida steviol daun stevia. Pereira et al.
(2016) melaporkan bahwa suhu dan total cahaya yang diterima oleh stevia mempengaruhi kandungan glikosida steviol pada stevia. Pada penelitian ini terlihat bahwa perbedaan klon stevia mempengaruhi waktu panen dan kandungan glikosida steviol. Kualitas daun stevia umumnya dikorelasikan dengan produksi glikosida steviolnya terutama steviosida dan reb A. Berdasarkan hasil produksi stevia pada 5 klon introduksi, terdapat 2 klon harapan untuk produksi reb A yaitu BS dan BP dengan produksi reb A mencapai $347 \mathrm{~kg} \mathrm{ha}^{-1}$ per tahun pada klon BS dan 290 $\mathrm{kg} \mathrm{ha}^{-1}$ per tahun pada klon BP (Tabel 4), sedangkan klon $\mathrm{BM}$ sesuai untuk produksi steviosida dengan hasil $248 \mathrm{~kg}$ $\mathrm{ha}^{-1}$ pertahun. Perbandingan antara semua klon introduksi yang diuji menunjukkan klon BM memiliki potensi yang paling baik untuk menghasilkan biomassa daun, TSG, dan steviosida. Cahaya mempengaruhi kandungan flavanoid tanaman Gynura pesudochina (Ghulamahdi et al., 2008).

Produksi TSG, steviosida, dan reb A yang dihasilkan pada penelitian ini lebih tinggi dibandingkan produksi di India dengan total steviosida dan reb A mencapai $157 \mathrm{~kg}$ $\mathrm{ha}^{-1}$ per tahun dengan adjustment populasi 111,111 tanaman per ha (Kumar et al., 2014) dan sebanding dengan produksi di Amerika Serikat yaitu rata-rata TSG $490 \mathrm{~kg} \mathrm{ha}^{-1}$ per tahun dan reb A $300 \mathrm{~kg} \mathrm{ha}^{-1}$ per tahun dengan populasi 90,000 tanaman per ha (Parris et al., 2016).

Tabel 4. Kandungan dan perkiraan hasil TSG, steviosida, dan rebaudiosida A dari lima klon stevia

\begin{tabular}{lrcccccc}
\hline \multirow{2}{*}{ Klon stevia } & \multicolumn{3}{c}{ Kandungan (\%) } & \multicolumn{4}{c}{ Perkiraan hasil $\left(\mathrm{kg} \mathrm{ha}^{-1}\right.$ per tahun) } \\
\cline { 2 - 8 } & TSG & Steviosida & Reb A & Daun kering & TSG & Steviosida & Reb A \\
\hline BM & 9.17 & 4.10 & 2.90 & 6,039 & 554 & 248 & 175 \\
BP & 9.84 & 1.50 & 6.62 & 4,382 & 431 & 66 & 290 \\
BS & 13.54 & 2.42 & 8.54 & 4,058 & 549 & 98 & 347 \\
BU & 6.73 & 1.60 & 2.23 & 1,629 & 110 & 26 & 36 \\
BX & 10.32 & 4.06 & 4.14 & 4,907 & 506 & 199 & 203 \\
\hline
\end{tabular}

Keterangan: $\mathrm{TSG}=$ total glikosida steviol; Reb $\mathrm{A}=$ rebaudiosida $\mathrm{A}$

\section{KESIMPULAN}

Uji adaptasi klon stevia introduksi di Bogor Indonesia memberikan hasil yang baik, apabila dilihat dari produktivitas, pertumbuhan maupun kandungan TSG, steviosida, dan reb A. Kelima klon stevia mulai berbunga pada waktu yang berbeda sehingga periode panennya juga berbeda. Klon terbaik yang menghasilkan produktivitas biomassa daun kering, TSG, dan steviosida tertinggi adalah klon BM, klon terbaik yang menghasilkan reb A tinggi adalah klon BS dan BP, sedangkan klon yang mampu menghasilkan steviosida dan reb A dalam jumlah yang hampir sama tinggi adalah klon BX. Dari hasil kajian produksi daun dan kandungan glikosida steviol maka klon yang potensial dikembangkan lebih lanjut adalah klon BM, BS, BX, dan
BP. Kajian dilakukan di dataran menengah yaitu $800 \mathrm{~m}$ dpl sehingga apabila akan dikembangkan di lokasi-lokasi lain maka keempat klon tersebut dapat digunakan sebagai sumber bahan tanam.

\section{DAFTAR PUSTAKA}

Carrieri, R., E. Cozzolino, P. Tarantino, D. Cerrato, E. Lahoz. 2016. First report of southern blight on candyleaf (Stevia rebaudiana) caused by Sclerotium rolfsii in Italy. Plant Disease 100:220.

Ceunen, S., J.M.C. Geuns. 2013a. Steviol glycosides: chemical diversity, metabolism, and function. J. Nat. Prod. 76:1201-1228. 
Ceunen, S., J.M.C. Geuns. 2013b. Influence of photoperiodism on the spatio-temporal accumulation of steviol glycosides in Stevia rebaudiana (Bertoni). Plant Sci. 198:72-82.

Ceunen, S., S. Werbrouck, J.M.C. Geuns. 2012. Stimulation of steviol glycoside accumulation in Stevia rebaudiana by LED light. Plant Physiol. 169:749-752.

Chatsudthipong, C., C. Muanprasat. 2009. Stevioside and related compounds: therapeutic benefits beyond sweetness. Pharmacology \& Therapeutics 121:4154.

Djajadi. 2014. Pengembangan tanaman pemanis Stevia rebaudiana (Bertoni) di Indonesia. Perspektif 13:2533.

[FAO] Food Agricultural Organization. 2010. Compendium of food additive specification. FAO JECFA Monograph. Roma, IT.

Ghulamahdi, M., S.A. Aziz, Nirwan. 2008. Peningkatan laju pertumbuhan dan kandungan flavonoid klon daun dewa (Gynura pseudochina (L.) DC) melalui periode pencahayaan. Bul. Agron. 36:40-48

Kamalakannan, A., V. Valluvaparidasan, K. Chitra, E. Rajeswari, K. Salaheddin, D. Ladhalakshmi, A. Chandrasekaran. 2007. First report of root rot of stevia caused by Sclerotium rolfsii in India. Plant Pathol. 56:350.

Kinghorn, A.D. 2002. The Genus of Stevia. Taylor \& Francis. London and New York, USA.

Koehler, A., H. Shew. 2014. First report of stem and root rot of Stevia caused by Sclerotium rolfsii in North Carolina. Plant Disease 98:1005.

Kumar, R., S. Sharma, S. Sood. 2014. Yield components, light interception and marker compound accumulation of stevia (Stevia rebaudiana Bertoni) affected by planting material and plant density under western Himalayan conditions. Arch. Agron. Soil Sci. 1:115.

Mishra, P., R. Singh, U. Kumar, V. Prakash. 2010. Stevia rebaudiana - A magical sweetener. Global J. Biotechnol. Biochem. 5:62-74.
Mogra, R., V. Dashora. 2009. Exploring the use of Stevia rebaudiana as a sweetener in comparison with other sweeteners. J. Hum. Ecol. 25:117-120.

Mubiyanto, B.O. 1990. Analisis pertumbuhan tanaman Stevia rebaudiana Bertoni pada tiga tinggi tempat. Disertasi. Sekolah Pascasarjana. Institut Pertanian Bogor.

Nikolova, E. 2015. Development in the production of natural sweetener (Stevia rebaudiana) in Bulgaria. J. Environ. Agric. Sci. 3:61-71.

Parris, C.A., C.C. Shock, M. Qian. 2016. Dry leaf and steviol glycoside productivity of Stevia rebaudiana in the Western United States. Hort. Sci. 51:1220-1227.

Pereira, C., L. Storck, S.J. Lopes, T.N. Martin, D.A. Bisognin. 2016. Dry biomass and glycoside yield from Stevia rebaudiana leaves under different harvesting times. Biosci. J. 32:1462-1471.

Prakash, I., A. Markosyan, C. Bunders. 2014. Development of next generation stevia sweetener: Rebaudioside M. Foods 3:162-175.

Ramesh, K., V. Singh, N.W. Megeji. 2006. Cultivation of stevia (Stevia rebaudiana (Bert.) Bertoni): A comprehensive review. Adv. Agron. 89:137-177.

Shock, C.C., C.A. Parris. 2015. Stevia plant named 'SW 129'. U.S. plant patent application No. 14757095, filed 17 November 2015. S\&W Seed Co., Fresno, CA.

Shock, C.C., C.A. Parris. 2016. Stevia plant named 'SW 107'. U.S. plant patent US 2016/ 0157403 Pl, published 2 June 2016. S\&W Seed Co., Five Points, CA.

Suhendi, D. 1988. Seleksi massa tanaman Stevia rebaudiana Bertoni. Menara Perkebunan 56:93-95.

Sumaryono, M.M. Sinta. 2011. Peningkatan laju multiplikasi tunas dan keragaan planlet Stevia rebaudiana pada kultur in vitro. Menara Perkebunan 79:49-56.

Sumaryono, M.M. Sinta. 2015. Petunjuk teknis budidaya tanaman stevia. PPBBI. Bogor, ID.

Yadav, S.K., P Guleria. 2012. Steviol glycoside from stevia: biosynthesis pathway review and their application in food and medicine. Crit. Rev. Food Sci. Nutr. 52:988998. 